\title{
Gestational Age Estimation and Validation using Ultrasonic Measurements of Fetal Biparietal Diameter and Occipito Nasal Length in Nellore Brown Ewes
}

\author{
Kancharla Jyothi ${ }^{1 *}$, Guelal Sudha ${ }^{2}$, Kosaraju Mouli Krishna ${ }^{3}$, Annayappa Sahadev ${ }^{2}$, \\ Muniyappa Narayana Swamy ${ }^{4}$, Suguna Rao $^{5}$ and Manepanda Appaiah Kshama ${ }^{6}$ \\ ${ }^{1}$ Department of Veterinary Gynaecology \& Obstetrics, College of Veterinary Science, Proddatur, Sri Venkateswara Veterinary \\ University, Andhra Pradesh, INDIA \\ ${ }^{2}$ Department of Veterinary Gynaecology \& Obstetrics, Veterinary College, Hebbal, Bengaluru, Karnataka Veterinary, Animal \\ and Fisheries Sciences University, Karnataka. INDIA \\ ${ }^{3}$ Department of Veterinary Gynaecology \& Obstetrics, College of Veterinary Science, Tirupati, Sri Venkateswara Veterinary \\ University, Andhra Pradesh, INDIA \\ ${ }^{4}$ Department of Veterinary Physiology, Veterinary College, Hebbal, Bengaluru, Karnataka Veterinary, Animal and Fisheries \\ Sciences University, Karnataka, INDIA \\ ${ }^{5}$ Department of Veterinary Pathology, Veterinary College, Hebbal, Bengaluru, Karnataka Veterinary, Animal and Fisheries \\ Sciences University, Karnataka, INDIA \\ ${ }^{6}$ Department of Veterinary Clinical Complex, Veterinary College, Hebbal, Bengaluru, Karnataka Veterinary, Animal and \\ Fisheries Sciences University, Karnataka, INDIA \\ *Corresponding author: KJyothi; E-mail: jyothik100@gmail.com
}

Received: 27 Feb., 2021

Revised: 24 April, 2021

Accepted: 28 April, 2021

\begin{abstract}
Gestational age estimation in small ruminants helps in nutritional management of pregnant ewes and optimizes the lamb survival. Nellore Brown ewes $(n=20)$ were subjected to short day estrus synchronization protocol and weekly once transabdominal ultrasonography from day 8 onwards until parturition. The biparietal diameter and occipito nasal length of fetal head measured from day 43 until day 113 of gestation. A positive correlation was obtained between gestational age and BPD $(r=0.9687)$ and ONL $(r=0.9873)$ and regression equations generated as $y=15.94 \mathrm{x}+28.43$ and $y=9.471 \mathrm{x}+25.66$ respectively for BPD and ONL where $\mathrm{y}$ is GA and $\mathrm{X}$ is respective head measurements. For validation of equations, BPD and ONL were measured in 21 and 12 pregnant ewes respectively, in field test. For linear relationship 61.9 and $71.4 \%$ of pregnant ewes delivered within \pm 7 and \pm 14 days of expected parturition dates for BPD and 58.3, and $100 \%$ of pregnant ewes delivered within \pm 3 and \pm 11 days of expected parturition dates for ONL. It was concluded that the ultrasonic measurements of fetal head diameters were well correlated with gestational age and can be used for estimation of pregnancy duration, however, ONL was precise over BPD in predicting parturition dates in Nellore Brown ewes.
\end{abstract}

\section{HIGHLIGHTS}

(0 The fetal head diameters were used to estimate and validate gestational age in Nellore ewes

(0 The fetal occipito nasal length was proved better in correlation and prediction of lambing dates.

Keywords: Estrus Synchronization, Transabdominal ultrasonography, Correlation, Regression equation

Gestational age estimation in sheep provides their owners valuable information that aids in the late gestation management. Real time ultrasonography is useful in determining the duration of pregnancy. In small ruminants the most practical measurement of fetal structures are
How to cite this article: Jyothi, K., Sudha, G., Krishna, K.M., Sahadev, A., Swamy, M.N., Rao, S. and Kshama, M.A. (2021). Gestational age estimation and validation using ultrasonic measurements of feta biparietal diameter and Occipito nasal length in Nellore brown ewes. $J$. Anim. Res., 11(2): 325-331.

Source of Support: None; Conflict of Interest: None 
fetal head diameters (Karen et al., 2009). These can be observed from middle of first trimester to the end of second trimester of pregnancy and found to have high correlation with gestational age (Lee et al., 2005, Suguna et al., 2008). The data for the domestic breeds are scanty and the current paper presents analysis of data derived by transabdominal sequential ultrasonic measurements of bipariertal diameter (head width) and occipito nasal length (head length) in Nellore breed and validation of regression equations generated.

\section{MATERIALS AND METHODS}

Nellore Brown ewes $(n=20)$ aged 1-4 years reared under semi intensive conditions, with standard management conditions fed with greens, concentrates and adlib fresh water and salt licks were selected for the study. The ewes were subjected to estrus synchronization protocol of seven days using vaginal sponges and 300 IU of PMSG (Folligon, Intervet International, Boxmeer, Netherlands) and $75 \mu \mathrm{g}$ of PGF $_{2 \alpha}$ (Cloprostenol; Pragma, Intas Pharmaceutica Limited, Matoda, Ahmedabad) intra muscularly at sponge withdrawl. Upon sponge withdrawl the synchronized ewes were kept with a ram, color painted, and each day ram was replaced with a new one with changed color paint at brisket region. The next day of receiving last mating mark was treated as day 1, start of pregnancy. Transabdominal ultrasonography was conducted using a real time B mode scanning (ALOKA SSD 500, Aloka co Ltd, Japan) equipped with $5 \mathrm{MHz}$ convex transducer on mated ewes. Serial ultrasonographic examinations were carried out on weekly basis starting from day 8 of mating. Once embryonic vesicle was identified the pregnancy was confirmed and scanning was performed weekly till end of gestation. During scanning biparietal diameter and occipito nasal length were identified and images frozen, saved and measured with built in electronic callipers.

\section{Biparietal Diameter (BPD)}

It is the maximum diameter of the head width between two parietal bones and measured between day 43 to 113 (Fig. 1).

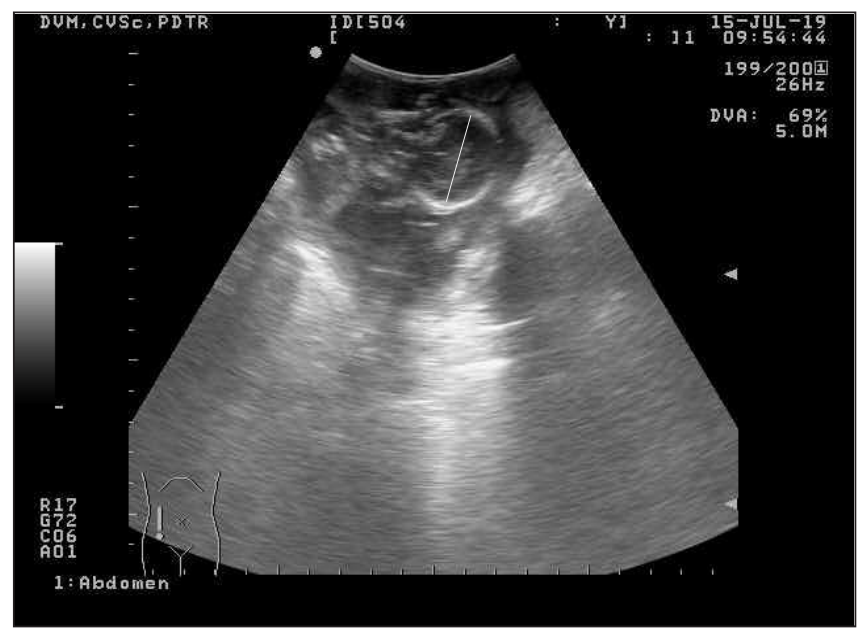

Fig. 1: Biparietal diameter measured in Nellore Brown ewes

\section{Occipito nasal length (ONL)}

The head length measured from the top of Os nasale to the end of Os occipital and measured between day 43 to 113 (Fig. 2).

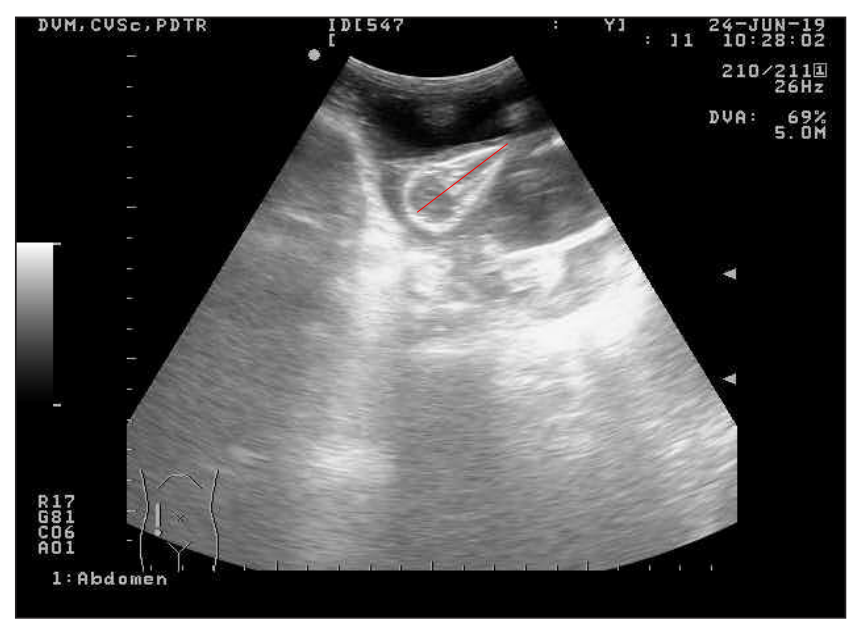

Fig. 2: Occipito nasal length measured in Nellore Brown ewes

\section{Field test}

The ewes were randomly subjected to ultrasound scanning in farmers' flocks in villages. BPD and ONL were measured in 21 and 12 pregnant ewes, respectively. The gestational age was estimated using the regression equations generated in experimental animals. The lambing dates were obtained from farmers and gestational age was 
calculated retrospectively taking the average gestation length as 148 days.

\section{Data analysis}

The relationship of gestational age with BPD and ONL was plotted as linear regression and the GA (days) was the independent variable $(\mathrm{y})$ and the head diameters $(\mathrm{cm})$ being the dependent variable (x), a 5\% level of significance was used using statistical packages for social sciences (SPSS) version 20. In the field test, Mean square errors method used to compare fetal parameters.

\section{RESULTS AND DISCUSSION}

By day 36, head and trunk of the embryo could be visualized, by day 43 , a clear organization of the fetus into head, neck and body was observed in this study and these findings were in agreement with Ali and Hayder (2007) and Valasi et al. (2017) who reported differentiation of embryo into head, body and limbs on $38 \pm 3.2$ and 35 days respectively. On the contrary, Kumar et al. (2015) reported organization of fetal body on day 42, later than recorded in this study while Santos et al. (2018) reported in $4^{\text {th }}$ week, earlier than observed in this study. In 1939, Cloette grossly observed these structures between days 28 and 35 after conception.

The Orbits of the eye observed as anechoic pockets, mandible, nasal bone ossification was noticed in few by day 43. Ossification of the head bones was observed by Day 50. Present findings were in corroboration with Ali and Hayder (2007) and Kumar et al. (2015) who reported skull ossification between 42 - 48 days of gestation and differed from Valasi et al. (2017), who reported mandible and orbit walls ossification on day 36 and head bones ossification on day 56. These differences could be attributed to breed variation (Kumar et al., 2015), individual differences and inability to establish precise timing of ovulation as well as fertilization (Valasi et al., 2017).

The BPD was detected from day 36 until end of pregnancy. However, measured between day 43 to 113 , after that the BPD exceeded the ultrasound screen length and obtaining images became difficult. Even though, head was detected from day 36, BPD could be measured in 50\% (10/20) of ewes only on day 43. However, by day 50 BPD was measurable in all ewes. Many authors (Sergeev et al.,
1990; De Bulnes et al., 1998; Airina et al., 2011; Santos et al., 2018 and Haq et al., 2020) measured BPD between day 32 and 125 in ewes and goats. Haibal and Perkins (1989) stated that it was not possible to obtain symmetrical images of skull before 40-50 days of pregnancy. Sergeev et al. (1990) opined that fetal skull was clear and defined between $49-84$ days and was easy to measure, however fetal positioning influenced the ease of obtaining an image suitable for measurement.

In present study, BPD could be measured in all ewes until day 99 , however on day 106 and day 113 , head width could not be measured in $20 \%$ and $45 \%$ ewes respectively either due to fetal positioning or fetal size. This was in agreement with findings of Haibel (1988) who stated that the BPD measurement becomes difficult after day 105 of gestation due to variability of fetal head location and posture which may be anywhere in the abdomen from the inguinal region to the xiphoid (Jones and Reed, 2017) and diminished uterine fluids as proportional to uterine contents often defies measurements of head in transabdominal position. Kelly and Newnham (1989) also experienced constraints in measurement of head width from about day 100-110 of gestation. It could be due to increasing calcification of bones and shadowing effects. Sergeev et al. (1990) were unable to measure head width in the later stages of their study between day 106 to 119 , due to inadequate depth of penetration of the $5 \mathrm{MHz}$ transducer employed. Haq et al. (2020) detected head occasionally after day 125 , in the last month of pregnancy. This difficulty was attributed to the increase in fetal size and compression of the head by other fetal parts (Amer, 2010).

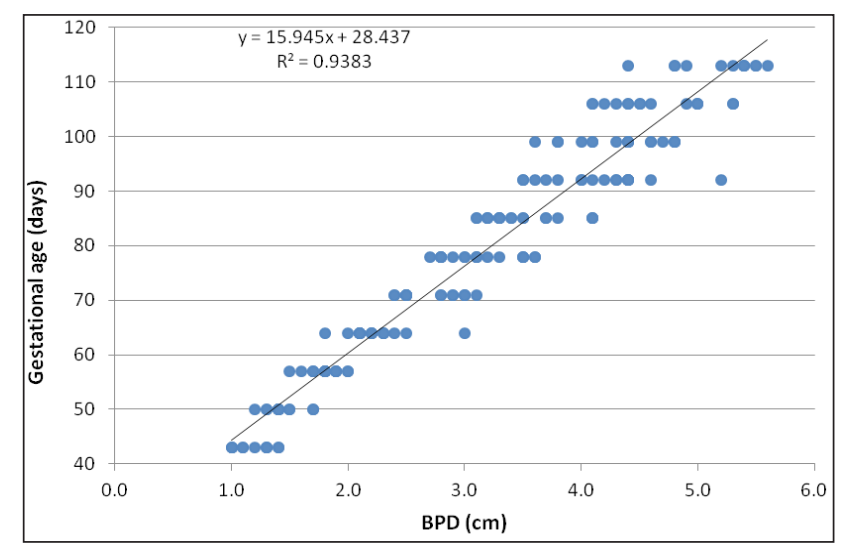

Fig. 3: Scatter plot and linear regression line of BPD and GA in Nellore Brown ewes 
A high positive correlation $\left(r=0.96867 ; R^{2}=0.938\right)$ was derived between GA and BPD in the present investigation. These results were in consistent with findings of Sergeev et al. (1990), De Bulnes et al. (1998) and Gunduz et al. (2010) who reported correlation as $r=0.961,0.96$ and 0.977 respectively between GA and BPD in sheep and goats. Kuru et al. (2018) also reported similar results in Abaza $\left(R^{2}=0.925\right)$ and Gurku $\left(R^{2}=0.928\right)$ goats.

However, higher correlation (0.97-0.99) was reported by Haibel (1988), Haibel and Perkins (1989), Raichle and Haibel (1991), Suguna et al. (2008) and Santos et al. (2018) between GA and BPD in sheep and goats than the present study. Lower correlation in the present study might be attributed to the fact that the scanning was extended to third trimester, the intervals between consecutive scanning and breed differences. BPD measurements at early gestational ages (day $40-50$ ) had moderate variability due to depth of the uterus in the abdomen (Haibel, 1988). In contrast some authors like Abdelghafar et al. (2011), Venkato et al. (2013) Petrujkic et al. (2016) and Haq et al. (2020) reported lower coefficient of determination (0.75 0.91 ) between GA and BPD in sheep and goats.

In the present investigation, ONL was detected from day 36 until end of parturition however measurements could be recorded between days 43 and 113. This was in consistent with Santos et al. (2018) who measured ONL from $6^{\text {th }}$ week of gestation, while De Bulnes et al. (1998) and Yazici et al. (2018) recorded ONL earlier than this study. However, Nwaogu et al. (2010) and Petrujkic et al. (2016) obtained measurements in later gestational days (from day 57 and day 46 respectively) than current study.

Nwaogu et al. (2010) measured ONL up to day 124 which is later than this study, While Kelly and Newnham, (1989), De Bulnes et al. (1998), Petrujkic et al. (2016), Santos et al. (2018) and Yazici et al. (2018) took measurements up to day 95, 91, 63, 98 and 74 respectively in sheep and goats. The limited observations made for ONL was due to specific fetal posture (Khan et al., 2015) or fetal dimensions exceeding the width of transducer in many ewes (Kelly and Newnham, 1989). From 13 week onward it was difficult to measure nasal to snout length due to fetal size, ultrasonographic characteristics, positioning difficulty and fetal movement (Santos et al., 2018).

A high positive correlation $\left(r=0.9873\right.$ and $\left.R^{2}=0.974\right)$ was established between ONL and gestational age in the present study. The correlation developed between ONL and GA was in accordance with the findings of Petrujkic et al. (2016) and Yazici et al. (2018). In contrast, De Bulnes et al. (1998), Nwaogu et al. (2010), Khan et al. (2015) and Santos et al. (2018) reported lower correlation ( $\mathrm{r}=0.7$ to 0.97).

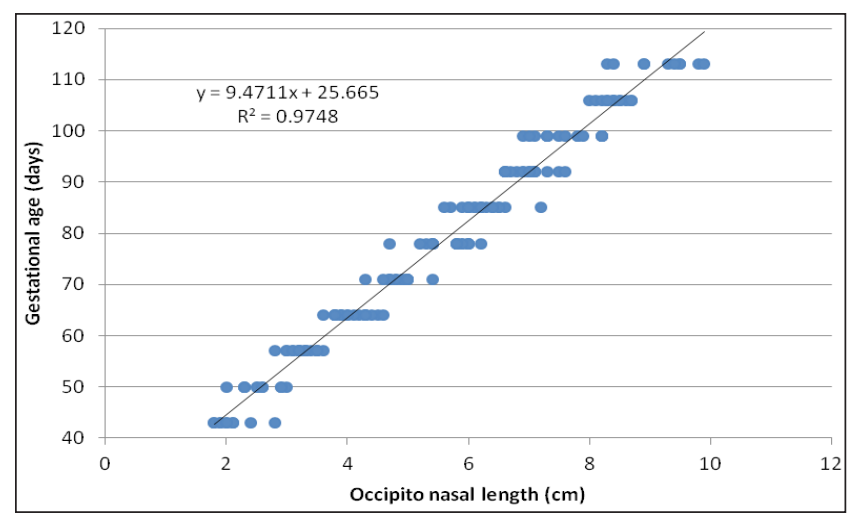

Fig. 4: Scatter plot and linear regression line of ONL and GA in Nellore Brown ewes

The mean BPD and ONL (Table 1) showed significant increase $(\mathrm{p}<0.05)$ during the measurement period.

Table 1: Range and Mean $( \pm \mathrm{SE})$ of BPD and ONL of fetus during pregnancy in Nellore Brown ewes

\begin{tabular}{lllll}
\hline \multirow{2}{*}{ GA } & \multicolumn{2}{c}{ BPD } & \multicolumn{2}{c}{ ONL } \\
\cline { 2 - 5 } & Mean \pm SE & Range & Mean \pm SE & Range \\
\hline 43 & $1.19 \pm 0.05^{\mathrm{a}}$ & $1.0-1.4$ & $2.08 \pm 0.10^{\mathrm{a}}$ & $1.8-2.8$ \\
50 & $1.43 \pm 0.04^{\mathrm{ab}}$ & $1.2-1.7$ & $2.54 \pm 0.09^{\mathrm{a}}$ & $2.0-3.0$ \\
57 & $1.80 \pm 0.03^{\mathrm{bc}}$ & $1.5-2.0$ & $3.25 \pm 0.05^{\mathrm{b}}$ & $2.8-3.6$ \\
64 & $2.22 \pm 0.06^{\mathrm{c}}$ & $1.8-3.0$ & $4.08 \pm 0.06^{\mathrm{c}}$ & $3.6-4.6$ \\
71 & $2.71 \pm 0.06^{\mathrm{d}}$ & $2.4-3.1$ & $4.85 \pm 0.06^{\mathrm{d}}$ & $4.3-5.4$ \\
78 & $3.13 \pm 0.07^{\mathrm{de}}$ & $2.7-3.6$ & $5.67 \pm 0.09^{\mathrm{e}}$ & $4.7-6.2$ \\
85 & $3.49 \pm 0.08^{\mathrm{e}}$ & $3.1-4.1$ & $6.22 \pm 0.09^{\mathrm{e}}$ & $5.6-7.2$ \\
92 & $4.14 \pm 0.11^{\mathrm{f}}$ & $3.5-5.2$ & $6.86 \pm 0.15^{\mathrm{f}}$ & $4.6-7.6$ \\
99 & $4.33 \pm 0.09^{\mathrm{fg}}$ & $3.6-4.8$ & $7.58 \pm 0.12^{\mathrm{g}}$ & $6.9-8.2$ \\
106 & $4.64 \mathrm{G}^{\mathrm{G}} \pm 0.11^{\mathrm{g}}$ & $4.1-5.3$ & $8.39 \pm 0.06^{\mathrm{h}}$ & $8.0-8.7$ \\
113 & $5.18 \pm 0.11^{\mathrm{h}}$ & $4.4-5.6$ & $9.19 \pm 0.17^{\mathrm{i}}$ & $8.3-9.9$ \\
\hline
\end{tabular}

*Means with different superscripts differ significantly $(\mathrm{p}<0.05)$ within columns.

\section{Validation of prediction equations in the field}

In the farmers flocks in 21 pregnant ewes BPD 
measurements were taken for validation and it was found that $61.9(13 / 21)$ and $71.4(15 / 21) \%$ of deliveries occurred within \pm 7 , and \pm 14 days of expected lambing dates. Amle et al. (2014) evaluated the equation developed by Abdelghafar et al. (2007) for BPD in Sangamneri and Osmanabadi goats ( $\mathrm{n}=10$ each) and found GA as 85.99 \pm 1.29 and $81.03 \pm 2.16$ days when observed GA was 88 and 81 days respectively. However, Haq et al. (2020) validated regression equation for $\mathrm{BPD}$ and recorded difference between actual and estimated day of gestational stage was $6.8 \pm 1.0$ days in Beetal goats $(n=20)$. In human fetuses the measurement of BPD before gestational week 20 predict the gestational age with an accuracy of $\pm 7-11$ days and the precision tolerance of BPD dimension decreased during the third trimester of pregnancy (Hadlock et al., 1991).

The regression equation for BPD used in this study was applicable between day 43 - 113 of gestation only. Further, the BPD measurements taken in the third trimester may not be true to its actual value due to fetal head positions which might lead to incorrect estimation of gestational age. Gestational age is best estimated by measurements in early pregnancy since at later gestational ages these measurements reflects the growth characteristics of the fetus rather than its age (Kurtz and Needleman, 1988). Prediction of GA would be increasingly unreliable from day 80 onwards due to differtial growth rates of skull even if accurate measurements were made as opined by Kelly and Newnham (1989).

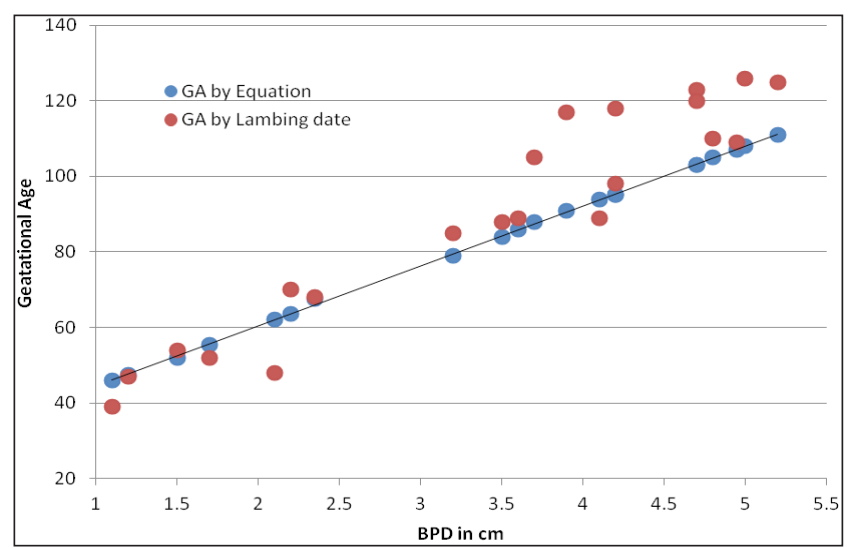

Fig. 7: Validation of Biparietal diameter measurements under field conditions

In farmers flocks in villages in 12 pregnant ewes ONL measurements were obtained and validated. 58.3 (7/12) and $100(12 / 12)$ per cent of ewes lambed within \pm 3 and \pm 11 days of expected lambing dates, respectively, for ONL The highest correlation $r=0.9873$ obtained for ONL in the present study justified more than $50 \%$ of deliveries occurring within \pm 3 days of expected dates. No previous literature for validation of ONL in field condition obtained.

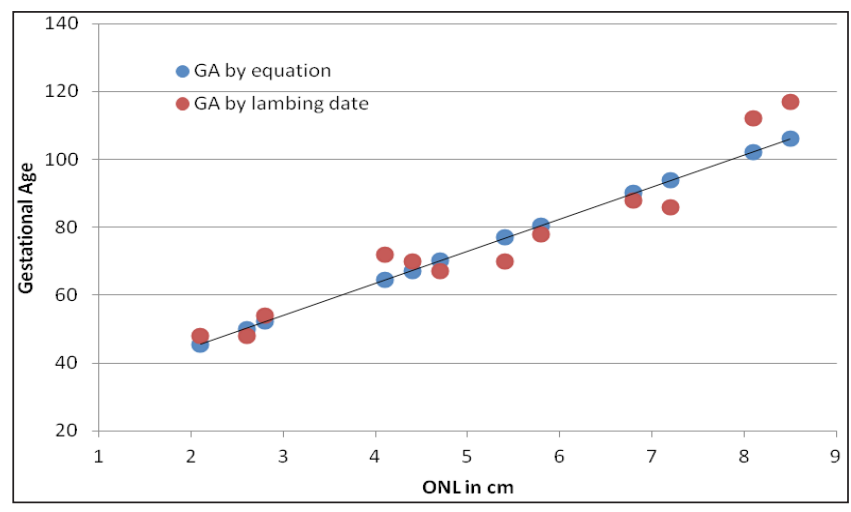

Fig. 7: Validation of occipito nasal length measurements under field conditions

\section{CONCLUSION}

It was concluded that the ultrasonic measurements of BPD and ONL of the fetus could be valuable in the estimation of gestational age and for the use of the regression formulae to predict the parturition under field conditions, however ONL measurements gave better prediction than BPD and it is recommended to conduct the study on large number of ewes.

\section{ACKNOWLEDGEMENTS}

The authors thank Sri Venkateswara Veterinary University, Tirupati, Andhra Pradesh and Karnataka Veterinary, Animal and Fisheries Sciences University, Bidar, Karnataka for providing facilities and funds to carry out research.

\section{REFERENCES}

Abdelghafar, R.M., Ahmed, B.H. and Bakhiet, A.O. 2007. Ultrasonic measurements of crown rump length and biparietal diameter to predict gestational age in Saanen goats. J. Anim. Vet. Adv., 6: 454-457.

Abdelghafar, R.M., Ahmed, B.H., Ibrahim, M.T. and Mantis, P. 2011. Prediction of gestational age by transabdominal real- 
time ultrasonographic measurements in Saanen goats (Capra hircus). Global Vet., 6: 246-351.

Airina, R.I., Nizam, A.M., Abdullah, R.B. and Khadijah. W.W. 2011. Using fetal-heart size measured from ultrasound scanner images to estimate age of gestation in goat. J. Anim. Vet. Adv., 10(19): 2528-2540.

Ali, A. and Hayder, M. 2007. Ultrasonographic assessment of embryonic, fetal and placental development in Ossimi sheep. Small Rumin. Res., 73: 277-282.

Amer, H.A. 2010. Ultrasonographic assessment of early pregnancy diagnosis, fetometry and sex determination in goats. Anim. Reprod. Sci., 117: 226-231.

Amle, M.B., Bakshi, S.A., Birade, H.S., Gulawane, S.U. and Bannalikar, A.S. 2014. Sonographic determination of fetal age in Sangamneri and Osmanabadi goats. Indian J. Anim. Reprod., 35(2): 36-38.

De Bulnes, A.G., Moreno, J.S. and Sebastián, A.L. 1998. Estimation of fetal development in Manchega dairy ewes by transrectal ultrasonographic measurements. Small Rumin. Res., 27(3):243-250.

Gunduz, M.C., Turna, O., Ucmak, M., Apaydin, S., Kasikci, G., Ekiz, B. and Gezer, N. I. 2010. Prediction of gestational week in Kivircik ewes using fetal ultrasound measurements. Agri. $J ., 5$ (2): 110-115.

Hadlock, F.P., Harrist, R.B. and Martinez-Poyer, J. 1991. How accurate is second trimester fetal dating?. J. Ultrasound Med., 10(10):557-561.

Haibel, G.K. 1988. Real time ultrasonic fetal head measurement and gestational age in dairy goats. Theriogenology, 30: 10531057

Haibel, G. K. and Perkins, N. R. 1989. Real-time ultrasonic biparietal diameter of secong trimester Suffolk and Finn sheep fetuses and prediction of gestational age. Theriogenology, 32: 863-869.

Haq, M.E.U., Hameed, N., Khan, M.I.U.R., Abbas, Q., Sohail, T., Rehman, A. and Mohsin, I. 2020. Temporal changes in physical signs of estrus and validation of fetal parameters for estimation of gestational stage through b-mode ultrasonography in beetal goats. Pak. Vet. J., http://dx.doi. org/10.29261/pakvetj/2020.037

Jones, A.K. and Reed, S.A. 2017. Benefits of ultrasound scanning during gestation in the small Ruminants. Small Rumin. Res., 149: 163- 171.

Karen, A.M., Fattouh, E.M. and Abu-Zeid, S.S. 2009. Estimation of gestational age in Egyptian native goat by ultrasonographic fetometry. Anim. Reprod. Sci., 114: 167-174.

Kelly, R.W. and Newnham, J.P. 1989. Estimation of gestational age in Merino ewe by ultrasound measurement of fetal head size. Aust. J. Agri. Res., 40: 1293-1299.
Khan, M.S., Ahmad, S., Zeb, M.T. and Khan, M.S. 2015. Gestational age estimation in kari sheep at different gestational length using trans-abdominal ultrasonographic fetometry. J. Anim. Health Prod., 23: 9-19

Kumar, K., Chandolia, R.K., Kumar, S., Pal, M. and Sandeep, K. 2015. Two-dimensional and three-dimensional ultrasonography for pregnancy diagnosis and antenatal fetal development in Beetal goats. Vet. World, 8(7): 835.

Kurtz, A.B. and Needleman, L. 1988. Ultra sound assessment of fetal age. In: Ultrasonography in Obstetrics and Gynecology Edt. Callen., P.W.W.B. Saunders Co., Philadelphia, Pennsylvania, pp. 47-64.

Kuru, M., Oral, H. and Kulaksiz, R. 2018. Determination of gestational age by measuring defined embryonic and foetal indices with ultrasonography in Abaza and Gurcu goats. Acta Veterinaria Brno., 87(4): 357-362.

Lee, Y., Lee, O., Cho, J., Shin, H., Choi, Y., Shim, Y., Choi, W., Shin, H., Lee, D., Lee, G. and Shin, S. 2005. Ultrasonic measurement of fetal parameters for estimation of gestational age in Korean black goats. J. Vet. Med. Sc., 67: 497-502.

Nwaogu, I.C., Anya, K.O. and Agadal, P. C. 2010. Estimation of foetal age using ultrasonic measurements of different foetal parameters in red Sokoto goats (Capra hircus) Veterinarski Arhiv., 80(2): 225-233.

Petrujkic, B.T., Cojkic, A., Petrujkic, K., Jeremic, I., Masulovic, D., Dimitrijevic, V., Savic, M., Pesic, M. and Beier, R.C. 2016. Transabdominal and transrectal ultrasonography of fetuses in Wurttemberg ewes: Correlation with gestational age. Anim. Sci. J., 87: 197-201.

Reichle, J.K. and. Haibel, G.K. 1991. Ultrasonic biparietal diameter of second trimester pygmy goat fetuses. Theriogenology, 35: 689-694.

Santos, V.J.C., Rodriguez, M.G.K., Da Silva, P.D.A., Mariano, R.S.G., Taira, A.R., De Almeida, V.T. and Vicente, W.R.R. 2018. B-mode ultrasonography and ecobiometric parameters for assessment of embryonic and fetal development in sheep. Anim. Reprod. Sci., 197: 193-202.

Sergeev, I., Kleemann, D.O., Walker, S.K., Smith, D.H., Grosser, T. I., Mann, T. and Seamark, R.F. 1990. Real time ultrasound imaging for predicting ovine fetal age. Theriogenology, 34: 593-601.

Suguna, K., Mehrotra, S., Agarwal, S.K., Hoque, M., Singh, S.K., Shanker, U. and Sarath, T. 2008. Early pregnancy diagnosis and embryonic and fetal development using real time B mode ultrasound in goats. Small Rumin. Res., 80: 80-86

Valasi, I., Barbagianni, M.S., Ioannidi, K.S., Vasileiou, N.G.C., Fthenakis, G.C. and Pourlis, A. 2017. Developmental anatomy of sheep embryos, as assessed by means of ultrasonographic evaluation. Small Rumin. Res., 152: 56-73. 
Vencato, J., Tormen, N., Bondesan, V., Milani, C. and Stelletta, C. 2013. Pregnancy ultrasound monitoring of endangered veneto's Local sheep breeds. $11^{\text {th }}$ Congress of the Italian Society of Animal Reproduction, June 19-22, Ustica, Italy.
Yazici, E., Ozenc, E., Celik, H.A. and Ucar, M. 2018. Ultrasonographic foetometry and maternal serum progesterone concentrations during pregnancy in Turkish Saanen goats. Anim. Reprod. Sci., 197: 93-105. 
